\title{
Research on the Employment Psychological Dilemma of Higher Vocational Graduates and Solutions Against the Background of Major Public Health Emergency
}

\author{
Weibo Qiu ${ }^{1, *}$ Penghao $\mathrm{Li}^{1}$ Xiyan Hua ${ }^{1}$ Daliang $\mathrm{Li}^{1}$ \\ ${ }^{I}$ Guangdong Nanhua Vocational College of Industry and Commerce, Guangzhou, Guangdong, China \\ *Corresponding author. Email: qiuweibo@nhic.edu.cn
}

\begin{abstract}
In the context of COVID-19 epidemic, the employment assistance of higher vocational colleges is mainly concentrated in employment recommendation, job-searching skills training, employment tracking and services, etc., and less attention is paid to the psychological dilemma of employment of higher vocational graduates, which is not conducive to employment of vocational graduates or the high-quality development of school employment. This paper uses empirical research methods and takes graduates of higher vocational education as the research objects. Through questionnaire surveys, 717 valid samples are obtained and 4 interviews are conducted. After data analysis, the following conclusions are drawn: 1. In the context of the epidemic, the employment situation of higher vocational graduates is very severe; 2 . Higher vocational graduates' expectations for future employment do not conform to objective reality; 3 . There is a certain gap between the requirements of companies for recruiting talents and the current objective conditions of fresh graduates; 4. Higher vocational graduates have inaccurate self-perception; 5. The personal job-hunting skills of vocational graduates are relatively insufficient; 6. The comprehensive ability of higher vocational graduates does not meet the requirements of social development; 7. Under the severe employment situation, the employment psychological conflicts of higher vocational graduates are fierce. On the basis of data analysis and discussion, the following suggestions are made: 1 . Higher vocational colleges should pay attention to the psychological status of students in employment, and carry out normalized investigation of student psychological status and assistance; 2. Higher vocational graduates improve self-awareness and relieve employment pressure in time; 3 . It is required to implement the precision and diversified training model of school-enterprise cooperation and collaborative education; 4 . The government strengthens guidance on the formulation of employment psychological assistance policies for colleges and universities; 5 . The school builds a student employment guidance work system that integrates career planning, employment guidance, and employment psychological assistance; 6. Higher vocational graduates should build up confidence, correctly attribute and improve their overall quality; 7 . The state maximizes employment opportunities, vigorously supports SMEs and encourages innovation and entrepreneurship, and stabilizes the fundamentals of college graduate employment; 8. The state should increase policy tilt to ensure that university graduates become a kite with constant line.
\end{abstract}

Keywords: Vocational graduates, Employment psychology, Dilemma, Solution path.

\section{INTRODUCTION}

\subsection{Raising the Question}

Coupled with the combined impact of various factors such as the decline of the CIER index, the outbreak of COVID-19 epidemic in 2020 has made the employment situation of higher vocational graduates very severe. COVID-19 epidemic has not only increased the difficulty of job selection for higher vocational graduates, but also increased the psychological burden in the process of job 
selection, resulting in sharp psychological fluctuations. Vocational college graduates appear various psychological dilemmas in the process of employment behavior and job selection. Literature studies have shown that the employment psychological problems of vocational graduates will directly affect graduates' choice of employment, and will also affect their high-quality employment. At the same time, related researches also show that good employment psychology can also achieve high-quality employment for higher vocational graduates and improve their employment satisfaction.

Therefore, it is of great urgency and theoretical significance to investigate and study the employment dilemma faced by higher vocational graduates under the background of major public health emergencies, especially the psychological dilemma of employment and practical countermeasures and suggestions.

\subsection{Current Research Status in China and Foreign Countries}

In the context of major public health emergencies, increasing the employment rate of vocational graduates, overcoming their employment psychological dilemma, finding a way to solve the employment psychological dilemma, and helping them achieve high-quality employment are of strong theoretical and practical significance. The project team conducted a search through CNKI on the subject of "Employment Psychology of Higher Vocational Graduates", and consulted 110+ documents. Through layers of retrieval and screening, studies are carried out on typical case, relationship, special perspective, problems and countermeasures, and foreign experience and enlightenment.

\subsubsection{Study on Typical Case}

Liu Yanfang, Gong Qiang, Zhang Bo, and Dong Zijin (2020)[1] took a university as an example to study the impact of local college graduates' employability under the epidemic. Wu Lingting, Li Yang, and Peng Ge (2020)[2] took a certain university in Hunan Province as an example to conduct research. It is found that college students encountered employment problems during the epidemic and proposed diversified governance. Yong Jiang and Min Zhou (2019) took a university as an example to explore the employment psychological problems of graduates, so as to adjust employment strategies for graduates through ideological and political education.

\subsubsection{Study on Relationship}

Gu Liang (2020)[3] explored innovative ways of integrating employment psychological dilemma with ideological and political ideas; Li Dayong and Wang Qiongyao (2020)[4] explored the employment psychology of graduates based on the practice of innovation and entrepreneurship guidance; Ouyang Zhongming, Huang Hui, and Wang Yanzi (2018)[5] focused on the career adaptability and graduate employment quality; Qi Ying (2020) studied the significance and path selection of promoting the employment of college students from the aspect of ideological and political education under the epidemic situation.

\subsubsection{Study on Special Perspective}

Zhang Deyi (2020) explored the employment quality and countermeasures of graduates from private higher vocational colleges based on the perspective of student care; Cao Xinjiang, Chen Ruili, Guo Weiyun, Zhang Kunpeng (2020) studied the employment psychological problems and countermeasures of agricultural graduates under the COVID-19 epidemic situation; Jiang Jin and Xing Yunkai (2018) built a comprehensive employment quality assurance system and evaluation system from a multi-subject perspective to achieve high-quality employment for graduates; Jiang Xinyan and Zhang Ye (2020) studied the employment psychological guidance method from the perspective of tourism management graduates under COVID-19 epidemic.

\subsubsection{Research on Problems and Countermeasures}

Geng Haixia, Zhao Youping, Ma Yuman and Song Bo (2020)[6] explored the employment problems and countermeasures faced by higher vocational colleges from the perspective of the epidemic; Xu Yang and Guo Qin (2021) analyzed the psychological problems and countermeasures of vocational college graduates' employment under the new normal epidemic situation; Chen Qi and Wang Jin (2019) focused on the employment psychological problems of vocational graduates and the analysis of their formation factors; Yang Yazong (2020) analyzed employment countermeasures of graduates from multiple perspectives; Gao Rong (2020) conducted research 
on the employment psychological problems and countermeasures of students in higher vocational colleges.

\subsubsection{Foreign Experience and Enlightenment}

Yue Huiling and Li Yawen (2016) explored the enlightenment of the reform of foreign vocational colleges to the employment quality of vocational graduates in Shaanxi Province; Peng Xinshe (2013) compared the differences in the employment quality of vocational graduates between China and the United States for enlightenment; Feng Yifu (2020) proposed that the "Sydney Agreement" has an important reference role in improving the quality of employment of graduates from higher vocational colleges; Liu Chunlin (2015) learned from the successful experience of vocational education in developed countries to deal with the problems in the development of vocational education in China.

It is worth mentioning that there is no document in CNKI on "Employment Psychological Dilemma of Higher Vocational Graduates" and "Employment Psychology of Higher Vocational Graduates Against the Background of Major Public Health Emergency". When searching "Employment Psychology of Higher Vocational Graduates" and "The employment path against the background of Covid-19 epidemic", there are less than 20 articles. When searching "Epidemic, Graduates, Employment", there are 93 academic journals, 4 copies of newspapers and periodicals, without the use of "employment psychological dilemma" as the research topic or keyword. This also proves once again that this project is of strong theoretical and practical significance. At the same time, it can make up for the lack of empirical research in this field, and provide practical countermeasures and suggestions for solving the employment psychological dilemma of higher vocational graduates.

\section{RESEARCH METHODS}

\subsection{Survey Objects and Contents}

- $\quad$ Survey Time

March-December 2020

- $\quad$ Survey Location

Some higher vocational colleges in Guangdong Province

- $\quad$ Survey Objects
(1) Survey objects: higher vocational graduates; (2) Interview objects: four employment counselors

- Survey Contents

Against the background of major public health emergencies, taking vocational college graduates in Guangdong Province as the main research objects, this paper investigates the employment situation and the employment psychological dilemma during this period;

It is necessary to understand the psychological dilemma and employment situation of vocational college graduates, the development of social employment and the introduction of relevant national employment policies;

It is required to reflect on the causes of employment difficulties and psychological difficulties of vocational college graduates, and put forward feasible countermeasures and suggestions based on data analysis, teacher interviews and references.

\subsection{Survey Methods and Tools}

\subsubsection{Questionnaire Survey}

Self-made Questionnaire on the Psychological Dilemma and Solution of Vocational College Graduates' Employment under the Background of Major Public Health Emergencies can be used to conduct online survey, and 717 valid questionnaires are recovered, with the effective rate of $100 \%$.

\subsubsection{Interview Method}

The teachers who work for the employment of higher vocational colleges were interviewed, and a self-made interview questionnaire named "Special Interview with Graduates" was used, with a total of 4 valid interviews.

\subsection{Research Procedures}

\subsubsection{Looking for Literature}

Before designing the questionnaire, the team members searched for and learned the literature closely related to the subject, and sorted out the relevant content from the literature. 


\subsubsection{Designing the Questionnaire}

It is required to sort out the content from the literature and conduct group discussion, and design a questionnaire.

\subsubsection{Recycling the Analysis Questionnaire}

717 valid questionnaires were collected. Further, SPSS17.0, Excel 2010, Word 2010 and other softwares were used to review and sort out the statistical questionnaire and screen the data, and the questionnaire data were analyzed and summarized.

\subsubsection{Writing a Survey Report}

Combined with literature review and data from the National Bureau of Statistics, a survey report was finally formed.

\section{DATA ANALYSIS}

\subsection{Basic Analysis of the Questionnaire}

The majors of vocational college graduates surveyed are mainly management majors.

According to the data, the students majoring in management account for the largest proportion $(48.80 \%)$, followed by students majoring in economics $(17.80 \%)$, and then the students majoring in other majors $(9.00 \%)$. It can be seen that more than six of the investigated vocational college graduates majored in management and economics.

Nearly $50 \%$ of the surveyed vocational college graduates have not yet found employment or internship units.

According to the data, $44.80 \%$ of the surveyed vocational college graduates have not yet found a job, followed by $21.50 \%$ of the surveyed vocational college graduates who plan to apply for a job, and $15.30 \%$ who have already found a contract company. This may be because most of the surveyed higher vocational college graduates face great difficulties in internship and employment, so the proportion of college students signing contracts with companies is relatively small. It may also be because some higher vocational college graduates choose to improve their academic qualifications through upgrading from junior college student to university student
Nearly $60 \%$ of the surveyed vocational college graduates choose employment areas mainly considering social and economic development and salary and welfare level.

According to the data, among the main factors for vocational college graduates to choose employment areas, "good social and economic development" accounts for the largest proportion $(32.20 \%)$, followed by "salary and welfare level" $(29.70 \%)$, and then "industry development level" (13.90\%). It can be seen that the main factor that vocational college graduates consider most about the employment area is the economic factor, which is also the current situation of contemporary social development.

The main ideal factors of vocational college graduates surveyed are good working environment, high economic income and personal interest.

According to the data, surveyed vocational college graduates believe that "good working environment" accounts for the largest proportion (76.00\%), followed by "ideal economic income" (75.50\%), and then "being in line with personal interests" (75.20\%). It can be seen that the ideal job elements in the heart of most vocational college graduates are assessed from various aspects such as working environment, economic income and personal interest.

The majority of vocational college graduates surveyed think that what are helpful to employment are: social practice experience, professional internship experience, and employment guidance provided by the school.

According to the data, $77.50 \%$ of the surveyed vocational college graduates think that social practice experience is the most helpful to them in job hunting, followed by professional internship experience $(65.00 \%)$ and career guidance provided by the university $(55.40 \%)$. Therefore, vocational college students should actively participate in social practice activities inside and outside the school, from which the accumulated experience and ability will contribute to their future employment.

Nearly $60 \%$ of the surveyed vocational college graduates encountered major difficulties in job hunting, including interview skills, lack of employment information or channels, and relevant internship experience.

According to the data, the main difficulties faced by vocational college graduates in job hunting are interview skills $(57.90 \%)$, lack of 
employment information or channels (54.50\%), and lack of relevant internship experience $(51.70 \%)$. It can be seen that most vocational college graduates can find their own problems in job interviews during job hunting.

Nearly $60 \%$ of the surveyed vocational college graduates think the employment situation is grim this year, with some difficulties.

According to the data, the surveyed vocational college graduates think the employment situation this year is "relatively grim and difficult" $(58.70 \%)$, followed by "very grim and difficult" (35.70\%), then "good situation, easy employment" and "not understanding the employment situation" (2.80\%). This may be due to the sudden COVID-19 epidemic this year, which leads vocational college graduates to feel that the employment situation is rather grim this year, increasing the employment pressure.

The vocational college graduates surveyed believe that the most effective way to find a job is the introduction of relatives and friends.

According to the data, among the effective ways for vocational college graduates to seek jobs, the average value of "job fairs of newspapers and media" is the highest (2.60), and the lowest is "introductions from relatives and friends" (2.34). The standard deviation of the two is small. It shows that higher vocational college graduates think that the most effective way to find a job is "introduction by relatives and friends", and there is little difference in the cognitive level between individuals.

The surveyed vocational college graduates believe that the preparation of job hunting for accumulating relevant internship experience is very important to the degree of influence on job selection.

According to the data, the average value of "reading job-related books" is the highest (2.14), and the lowest is the term of "accumulating relevant internship experience" (1.87). The standard deviation of the two is large. It shows that higher vocational college graduates think that "accumulating relevant internship experience" is very important for career selection, but there is a great difference in the cognitive level among individuals.

The vocational graduates surveyed think communication skills and moral character are more important to job hunting.
According to the data, among the personal abilities that vocational college graduates think are important to job hunting, "competitive ability" and "innovation ability" have the highest mean value (1.88), while "communication ability" and "moral quality accomplishment" have the lowest mean value (1.80), and the standard deviation of the two is large. It shows that higher vocational college graduates think that "communication ability" and "moral quality cultivation" are important for job hunting, but there is a big difference in the cognitive level among individuals.

Nearly $50 \%$ of vocational college graduates surveyed think they face great employment pressure.

According to the data, nearly $50 \%$ of the surveyed vocational college graduates think that they are facing great employment pressure $(48.10 \%)$, followed by great pressure $(31.40 \%)$, and then moderate pressure $(18.40 \%)$. It can be seen that the majority of vocational college graduates surveyed believe that they are facing greater employment pressure now.

The vocational college graduates surveyed think they have a good understanding of their own personalities.

According to the data, from vocational college graduates' understandings, the term "the job I expect must be related to my major" has the highest mean value (2.54), while the term "I know my personality well" has the lowest value (2.17), with the former having a larger standard deviation and the latter having a smaller standard deviation. It shows that the higher vocational college graduates surveyed think that they are very familiar with their own personalities, and the differences between individuals are small.

More than $40 \%$ of vocational college graduates surveyed feel pressure when they see other students have ideal jobs, which will affect them.

According to the data, when vocational college graduates surveyed see other students have ideal jobs, they feel the most pressure, which affects them $(41.60 \%)$, followed by the term "there are some pressures, but the students can adjust" (26.40\%), then the term "having very pressure, especially being anxious" (15.80\%). It can be seen that more than $50 \%$ of the surveyed vocational college graduates feel great pressure when they see that other students have ideal jobs, which will affect their own psychological state of employment. 
The majority of vocational college graduates surveyed believe that they should accept the results of their job applications happily if the results do not meet their expectations.

According to the data, the surveyed vocational college graduates think that when the job results do not meet their expectations, they choose to "adjust their mentality and accept happily" (60.20\%), followed by "make do first" (29.80\%), and "give up, if they do not meet their expectations, they will not wronged themselves" $(6.70 \%)$. This may be the common phenomenon that vocational college graduates cannot find their ideal jobs against the background of major public health emergencies. In a word, vocational college graduates should know how to adjust their mentality and accept it happily.

More than $40 \%$ of the surveyed vocational college graduates choose to solve their employment psychological problems by themselves.

According to the investigation of the solution for the employment psychological problems of graduates, they choose "to solve psychological problems independently", accounting for the largest $(45.30 \%)$, followed by the term of "asking parents, friends and so on to solve psychological problems" $(34.90 \%)$, then the term of "turning to professional psychological mechanism to solve the psychological problem" (8.60\%). In a word, most vocational college graduates will choose to solve the psychological problems caused by employment by themselves. This may be because there is a generation gap between them and their parents, they cannot effectively communicate with each other, or they think that the school does not provide much help in psychological employment.

Higher vocational college graduates surveyed believe that major factors have a greater influence on the formation of psychological pressure in employment.

According to the data, among the factors affecting the formation of psychological pressure of vocational college graduates surveyed, the mean value of "gender factor" is the highest (2.56), the lowest is "professional factor" (2.29), and the standard deviation of the two factors is large. It shows that vocational college graduates think that "professional factors" have a great influence on the formation of employment pressure, but there is a great cognitive difference between individuals.

Most of the investigated vocational college graduates' current employment psychological problems include anxiety, inferiority and fear.
According to the data, the main psychological problem of vocational college graduates surveyed is "anxiety" (89.00\%), followed by "inferiority" $(64.40 \%)$ and "fear" $(53.10 \%)$. In a word, vocational college graduates should make timely psychological preparation during the epidemic, and pay more attention to their own psychological conditions.

Most of the surveyed vocational college graduates have serious anxiety.

According to the data, in terms of the psychological problems and the degree of the surveyed vocational college graduates, the mean value of "conceit" and "jealousy" is the highest (3.66), and the lowest is "anxiety" (3.18), with large standard deviations. It shows that the psychological anxiety phenomenon is widespread among vocational college graduates, and the degree is deep, but the cognitive difference between individuals is great.

Most of the vocational college graduates surveyed hope that their schools or colleges will carry out special lectures on psychological counseling for employment and online and offline publicity and education on psychological adjustment for employment.

According to the data, the surveyed vocational college graduates hope their schools or colleges to carry out special lectures on psychological counseling in employment $(64.30 \%)$, to carry out online and offline publicity and education on psychological adjustment knowledge in employment $(54.40 \%)$, and to carry out special hotline for psychological counseling in employment $(52.60 \%)$. It can be seen that most vocational college graduates hope their schools or colleges to carry out special lectures on psychological counseling in employment.

\subsection{Cross-analysis of Questionnaires}

\subsubsection{Cross-analysis of Specialty and Employment Pressure}

How to cross-analyze the employment pressure faced by specialties and vocational college graduates? $\mathrm{P}=0.024<0.05$. According to the data, the surveyed vocational college graduates majoring in agricultural medicine feel that they are facing great employment pressure $(70.00 \%)$, which may be because the students majoring in agricultural medicine have more learning content and a heavy burden, and the employers have high requirements 
on such students. Next came to the students majoring in journalism and media $(50.00 \%)$, which may be because there are more and more students majoring in journalism and media at present, and the employment competition is increasing. Third came to students majoring in politics and law (48.65\%), which may be due to higher professional requirements on students majoring in politics and law.

\subsubsection{Cross-analysis of the Relationship Between Current Employment or Internship Status and Employment Pressure}

A cross-analysis of the current employment or internship status of vocational college graduates and the size of employment pressure they face is made. According to $\mathrm{P}=0.037<0.05$, it shows that the highest proportion $(75.00 \%)$ of the surveyed higher vocational college graduates who plan to study abroad and are under great employment pressure may be due to the fact that the higher vocational college graduates who plan to study abroad have to compete with domestic and foreign graduates in job selection and face greater employment pressure. Secondly, $69.23 \%$ of those who plan to work as freelancers face high employment pressure, which may be because those who plan to work as freelancers think that employment and income are not stable, and they are likely to have high employment anxiety and pressure. Third, those who have not yet found a job and are facing a lot of employment pressure $(52.65 \%)$, which may be because in the severe employment situation, vocational college graduates feel anxious and have a lot of employment pressure because they have not yet found a job. It can be concluded that higher vocational college graduates with different employment or internship status are facing greater employment pressure.

\section{SUMMING-UP}

In the context of the epidemic, the employment situation of vocational college graduates is very grim.

Affected by the epidemic, China's economic development is stagnant. Small and medium-sized enterprises have laid off employees and closed down, and the demand for recruitment has decreased, the number of unemployed people has increased, and the number of job-seekers has increased. The CIER index for college students dropped significantly (from 2.18 to 1.43), indicating a significant imbalance between supply and demand in the job market.

Vocational college graduates' expectations of future employment do not conform to the objective reality.

According to the survey data, most vocational college graduates have high expectations for future employment, including good working environment, high economic income and meeting personal interests, etc. However, affected by the epidemic, it is more difficult to obtain employment and achieve their employment goals.

There is a certain gap between the recruitment requirements of enterprises and the current objective situation of fresh graduates.

According to the survey results, the majority of vocational college graduates $(76.3 \%)$ want to work in megacities such as Guangzhou and Shenzhen. Due to the rapid economic development of super cities such as Guangzhou and Shenzhen, the salary and welfare level is relatively high, which meets the salary expectation of vocational college graduates and can provide more employment opportunities for vocational college graduates. However, enterprises in supercities have high requirements for recruiting talents and many conditions. However, fresh graduates lack work experience and compete with former graduates and unemployed people, so there is a certain gap with expectations.

Vocational college graduates have an inaccurate self-perception.

The survey data shows that higher vocational college graduates think that they have a better understanding of themselves and their personal characteristics have a deeper impact on their selfpositioning. However, there may be a gap between self-positioning and reality. In the face of the employment competition of higher vocational college graduates at the same level, students are prone to excessive competition, strong sense of self-esteem, comparison and other bad psychology, as well as negative psychological state of employment, thus increasing their employment pressure.

Higher vocational college graduates have relatively insufficient personal job-hunting skills.

It is mainly reflected in the following aspects, such as lack of resume making skills, job interview skills and professional internship experience and 
other experiences, resulting in increased pressure in the process of job hunting.

The comprehensive ability of vocational college graduates does not meet the requirements of social development.

It is mainly is reflected in the following aspects, such as insecure professional knowledge, lack of relevant professional skills certificates. In the process of job hunting, the lack of self-confidence and other psychological conditions may lead to the increased employment pressure.

Under the severe employment situation, the employment psychological conflicts of higher vocational graduates are fierce.

The survey results show that most vocational college graduates will have employment psychological problems under the severe employment situation and fierce social competition, which are manifested as anxiety (89.00\%), inferiority $(64.40 \%)$ and fear $(53.10 \%)$. Among them, there is widespread psychological anxiety phenomenon, and the degree is deeper. However, most vocational college graduates can rationally view and actively face these psychological problems, know how to self-regulate and seek help from outside, and show a confident attitude.

\section{COUNTERMEASURES AND SUGGESTIONS}

Higher vocational colleges should pay attention to the psychological status of students in employment, and carry out the investigation and support of the psychological status of students in a normal way.

In view of the employment psychology of higher vocational college graduates, higher vocational colleges should take an active role in constructing the dynamic supervision, investigation and early warning mechanism of employment psychology. With the help of using professional employment psychological assessment tools, such as Belbin team test, MBTI occupational personality test, it is necessary to regularly carry out the investigation and archive of students' psychological status and establish a long-term mechanism of college students' psychological quality education.

Higher vocational college graduates improve their self-awareness and relieve employment pressure in a timely manner.
In the process of job hunting, vocational graduates should know how to treat them rationally, objectively analyze, make correct attributions, and adopt self-catharsis, empathy, and relaxation practice methods when they encounter setbacks, shrinkage, and even fear in the process of job hunting, actively participate in appropriate psychological training and seek help from the school psychological counseling center to relieve employment pressure in a timely manner. Students can be more relaxed to face the challenges encountered in the process of job selection and employment.

It is necessary to implement the precise and diversified training mode of school-enterprise cooperation and collaborative education.

With the support of the government special fund, it is required to strengthen college students' employment psychological guidance in the traditional pattern of university-enterprise cooperation, carry out various forms of cooperation, such as joint development, and help graduates to achieve smooth transition from school to the enterprise, carry out targeted on-the-job training and mentoring for the in-post vocational graduates, alleviate the inadaptability of graduates in the early stage of employment and improve their confidence in employment and job security.

The government should strengthen the guidance for colleges and universities to formulate employment psychological support policies.

By deepening the reform, the institutional obstacles that hinder the formulation of employment psychological support policies in colleges and universities should be removed. Special funds should be set. It is required to increase the investment in the long-term mechanism of college students' psychological quality education from a macro perspective, guide colleges and universities to set up professional employment psychological training institutions, promote colleges and universities to successfully build a complete supporting facilities of employment psychological support system, and strengthen the publicity of graduates' employment psychological support policies. From the macro perspective, it is required to increase the social attention to the employment of psychological problems of graduates, and ask schools, families and students to pay attention to employment, so as to avoid psychological problems in time. 
The university establishes a student employment guidance system integrating career planning, employment guidance and employment psychological support.

Traditional employment guidance in higher vocational colleges involves almost nothing in employment psychology. In order to change this kind of situation, colleges need to raise the attention. The employment psychological help of graduates should be included in the employment guidance, and relevant theoretical guidance courses should be formulated to popularize and publicize the employment psychological knowledge to graduates, so as to help vocational graduates understand the matching degree of their own character and occupation. In the career planning, colleges should provide methods to alleviate students' employment psychological problems. At the same time, it is required to take practical operational guidance.

Higher vocational college graduates should have the confidence and correct attribution and improve their comprehensive quality.

The key to solve the dilemma of employment psychology is that graduates should have excellent comprehensive quality, especially psychological quality. Graduates should establish confidence, improve the level of cognition, keep pace with The Times, strengthen their own learning, and improve their social ability, strain ability, psychological ability to resist pressure, adaptability, innovative employment ideas.

The state has made maximum efforts to increase employment opportunities, vigorously support small and medium-sized enterprises and encourage innovation and entrepreneurship, so as to stabilize the employment fundamentals of college students.

It is necessary to formulate preferential policies for grassroots employment to encourage college students to find jobs at the grassroots level, with the focus on increasing recruitment in sectors such as basic education, grassroots medical care and community services.It is better to support college students to start their own businesses, give tax and other preferential policies, support innovative enterprises, and provide better entrepreneurial opportunities.

The government should increase the policy inclination to ensure that vocational graduates become kites.
During the university, more fresh graduates are encouraged to enlist in the army or participate in special activities such as the Western China Plan and the project "three supports and one assistance". Higher vocational colleges should strengthen the promotion of the policy and increase the intensity of enrolment recommendation. In a comprehensive consideration of the carrying capacity of colleges and universities, as well as the disciplines needed to support the national strategy and the majors in short supply for social development and other factors, on the premise of ensuring the quality of undergraduate training, efforts will be made to expand the enrolment scale of students who join a class in the middle of the course this year.

\section{CONCLUSION}

Employment is the most important aspect of people's livelihood. Against the background of major public health emergencies, the study of higher vocational graduates' employment psychological dilemma is carried out. This paper analyzes the causes, and put forwards corresponding solving strategy, which is of important meaning to hold the employment base of higher vocational graduates, promote higher vocational graduates' employment, improve the quality of employment, as well as to promote the healthy development of the economic and social quality.

\section{AUTHORS' CONTRIBUTIONS}

Penghao Li and Xiyan Hua are responsible for experimental design, Daliang Li analysed data, and Weibo Qiu wrote the manuscript and contributed to revising and editing.

\section{ACKNOWLEDGMENTS}

Fund: This paper is supported by the results of Special Fund of 2021 Guangdong Science and Technology Innovation Strategy ("Climbing Plan")(project number: pdjh2021a0854).

\section{REFERENCES}

[1] Liu Yanfang, Gong Qiang, Zhang Bo, Dong Zijin. An Empirical Study on the Impact of Local College Graduates' Employment Ability under the Epidemic — Taking Yuncheng University as an Example [J]. China Employment, 2020(09)_52-54. (in Chinese) 
[2] Wu Lingting, Li Yang, Peng Ge. Survey and Strategy of Employment of Higher Vocational College Graduates in Hunan Province under COVID-19 Epidemic Situation —Taking Hunan Industry Polytechnic as an Example [J]. China University Students Career Guide, 2020(12): 36 -42. (in Chinese)

[3] Gu Liang. Innovative research on the employment psychological dilemma and ideological and political coupling of college students in the new era [J]. Liaoning Economics, 2020(10): 74-75. (in Chinese)

[4] Li Dayong, Wang Qiongyao. Research on the Influence of Innovation and Entrepreneurship Guidance Practice on College Students' Employment Psgchology [J]. Shaanxi Radio and TV University Journal, 2020, 22(03)_2325. (in Chinese)

[5] Ouyang Zhongming, Huang Hui, Wang Yanzi. The Relationship between Career Adaptability and Employment Quality of Vocational College Graduates [J]. Research in Educational Development, 2018, 38(11) 4854. (in Chinese)

[6] Ma Yuman, Song Bo. Novel Coronavirus Pneumonia in Hebei Province University Students Employment Problem Research[J]. Hebei business, 2020 (10): 64-65.(in Chinese) 